\title{
Eye Worm infection in a Cattle - A Case Report
}

\author{
Balam Deepthi* and C Yalavarthi \\ Veterinary Dispensary, \\ Kolcharam, Medak dt. AndhraPradesh, India \\ Andhra Pradesh* Corresponding author email: drdeepthib@gmail.com \\ Received: 17-10-2011, Accepted: 10-11-2011, Published Online: 05-01-2012 \\ doi: $10.5455 /$ vetworld.2012.236-237
}

\section{To cite this article :}

Deepthi B and Yalavarthi Y (2012) Eye Worm infection in a Cattle - A Case Report, Vet. World. 5(4):236-237, doi: 10.5455/vetworld.2012.236-237.

\section{Introduction}

The genus Thelazia (Spirurida, Thelaziidae) includes a cosmopolitan group of eye worm spirurids responsible for ocular infections in domestic and wild animals and transmitted by different species of muscids. Eye worms (Thelazia spp) are common parasites of cattle and horses in many countries. Cattle are infected primarily by $T$ gulosa, T skrjabini, and T rhodesii; the latter is the most common and harmful to cattle in many countries. Horses are infected mainly by $T$. lacrymalis. These worms live in the conjunctival sac (eyelid) of the eye in many species of livestock. The worms are up to $2 \mathrm{~cm}$ long and are thin and white. One or both eyes may be affected. Upto 90 parasites have been found in one eye (Soulsby, 1982). Infections may be found year-round, but clinical disease outbreaks, particularly in cattle, usually are associated with the warm season activities of the flies. The present paper deals with a case of an eye worm infection in cattle and it's recovery.

\section{Case History}

A five year old cow and in second parity belonging to local farmer was presented to the Veterinary Dispensary, Kolcharam, Medak dt. AndhraPradesh with the history of conjunctivitis, cloudiness and corneal opacity in left eye. Further the anamnesis revealed that the animal was not respon-ding to the antibiotics.

\section{Clinical observations}

The animal was dull, depressed and anorectic with severe conjunctivitis, conjunctival edema in left eye. Vital signs like body temperature, pulse and respiration were within normal range. On detailed clinical examination an eye worm (Thelazia sps) was seen wriggling in the eye with vigorous movement.

\section{Treatment}

Primarily the eye worm was removed surgically according to the standard procedures after instillation of a local anesthetic in the left eye. The eye was thoroughly irrigated with aqueous solution of Boric powder. Concurrent use of Ciplox-D (Ciprofloxacin and dexamethasone) eye drops every 8 hours for 5 days was recommended for the suppression of inflammation and secondary bacterial infections. Ivermectin was injected subcutaneously @ $0.2 \mathrm{mg} / \mathrm{Kg}$ body weight. Animal was recovered completely.

\section{Discussion}

Feeding habits of the face flies, Musca larvipara and Musca convexifrons include a preference for ocular secretions, which is ideal for transmission. The first larvae of $T$. rhodesii enter the gut of the fly and penetrate the ovarian follicles, where they develop, becoming second larvae which grow and moult to become third larvae, infective larvae. The third larvae leave the ovarian follicles and migrate to mouthparts of the fly, from which they are transferred to cattle (Klesov, 1950). Development of sexually mature worms takes about 1-4 weeks in cattle. Adult parasites are found behind the nictitating membrane, on the surface of the conjunctiva and in lacrimal and naso lacrimal ducts.

The worm has a rough cuticle (skin) that causes irritation and inflammation to the cornea. Invasion of the lacrimal gland and excretory ducts may cause inflammation and necrotic exudation. Mild to severe conjunctivitis and blepharitis are common. cornea may get inflamed, ulcerated, perforated and if un attended, may get fibrosed at a later stage, particularly with $T$. rhodesii infection in cattle.

Certain systemic anthelmintics were found 
effective against eye worms. In cattle, levamisole at 5 $\mathrm{mg} / \mathrm{kg}, \mathrm{SC}$, and ivermectin and doramectin (Kennedy and Phillips, 1993), both at $0.2 \mathrm{mg} / \mathrm{kg}, \mathrm{SC}$ or IM, have shown activity against Thelazia spp. Pour-on formulations of ivermectin or doramectin, delivered to achieve a dosage of $0.5 \mathrm{mg} / \mathrm{kg}$, were also proven highly effective.

\section{References}

1. Kennedy M J and Phillips F E, (1993) Efficacy of doramectin against eyeworms (Thelazia spp.) in naturally and experimentally infected cattle. Veterinary parasitology. 49(1) 61-66.

2. Klesov M D, (1919) The biology of two nematodes of the genus Thelazia Bose, 1819, parasites of the eye of cattle. Dokl. Akad. Nauk. S.S.S.R., 70, 549-551.

3. Soulsby E J L, (1982) Textbook of Helminths, Arthropods and Protozoa of domesticated animals, Seventh edition, Pages 289-291.

$* * * * * * * *$ 